\title{
Antimicrobial Susceptibility of Respiratory Isolates from Homeless Population in an Urban Environment
}

R. Carberry (Rita Carberry)1,3, M. Olah (Michael Olah)3), V. Krcmery (Vladimir Krcmery) 2,4,5, G. Mikolasova (Gertruda Mikolasova)2,3, K. Prochazkova (Katerina Prochazkova) ${ }^{3}$, M. Stankovicova (Maria Stankovicova)33, M. Karvaj (Marian Karvaj)2,4, L. Radkova (Libusa Radkova)2,4, M. Hardy (Maria Hardy)2,4 J. Benca (Juraj Benca) 2,4, L. Bucko (Ladislav Bucko)2,4, V. Hulkova (Viera Hulkova) ${ }^{4}$, I. Bartosovic (Ivan Bartosovic) ${ }^{4}$, P. Slovak (Peter Slovak) ${ }^{4}$, R. Vlcek (Robert Vlcek) ${ }^{4}$, M. Mrazova (Mariana Mrazova)2, A. Liskova (Anna Liskova)2, M. Fasko (Marian Fasko)3,5, J. Kmec (Jozef Kmec)5 5. Szydlowski (Steve Szydlowski)', M. Franz (Mellinghoff Frank) ${ }^{5}$, S. Poptrajanovski (Slavko Poptrajanovski) ${ }^{5}$, E. Grey (Eva Grey) ${ }^{3,5}$ and M. Jankechova (Monika Jankechova)²

${ }^{1}$ Panuska School of professional studies, Depth of Health Administration, USA

2 Tropical Institute of St. Elisabeth University, SK

${ }^{3}$ Resoty and Mea Culpa Dormitory, Bratislava, SK

${ }^{4}$ Institute of Microbiology of Commenius University, School of Medicine, SK

5 St. Elisabeth PhD Program Bratislava, SK

\section{E-mail address:}

michalolah@gmail.com

\section{Reprint address:}

Michael Olah

i-GAP Vienna

International Society of Applied Preventive Medicine

Erdbergstrasse 33

1090 Vienna, AT

Suource: Clinical Social Work and Health Intervention Pages: $11-14$
Volume: 8

Issue: 1

\section{Reviewers:}

Dr. Gabriela Lezcano, Ph.D.

University of California

San Francisco, USA

Dr. Katerina Mullera

MPC Center Eldoret, KE 


\section{Key words:}

ATB resistance, Respiratory infections, Homeless population.

\section{Publisher:}

International Society of Applied Preventive Medicine i-gap

CSWHI 2017; 8(1): 11 - 14; DOI 10.22359/cswhi_8_1_02 @ 2017 Clinical Social Work and Health Intervention

\section{Abstract:}

Resistance to ATB from respiratory isolates of homeless residents with symptoms of URTI in 2012 - 2017 were analyzed. Resistance was tested in years 2008, 2012 and 2016 with no major resistance patterns found. MRSA resistance was less than $5 \%$ and PR less than $3 \%$ of all isolates. Despite majority of increasing population is not vaccinated against $\mathrm{H}$. influenza and St. pneumonia, influenza, no major ID outbreaks were present and no case of TB was noted.

\section{Conflict of interests:}

The authors whose names are listed in the title of the article certify that they have NO affiliations with or involvement in any organization or entity with any financial interest (such as honoraria; educational grants; participation in speakers' bureaus; membership, employment, consultancies, or other equity interest), or non-financial interest (such as personal or professional relationships, affiliations, knowledge or beliefs) in the subject matter or materials discussed in this manuscript.

\section{Introduction}

The number of homeless population in the EU is increasing. The homeless population may be at risk of certain communicable diseases such as tuberculosis, hepatitis B, C, HIV, pediculosis, scabies and other skin and soft tissue infections. Some areas with high appearance of homeless people experienced epidemics of MRSA and other outbreaks. (1-5) The aim of this communication was to describe common ID in two outpatient health care facilities for homeless in 20122017 in Bratislava; screening for about half a million permanent citizens of capitol and 100,000 migrating population on a daily basis from surrounding cities.

\section{Patients and Methods}

From December 2012 to January 2017, we have recorded more than 6,000 visits of homeless between the ages 19 to 86 . Ambulatory treatment was offered for the majority of cases after assessment of their health status, either in the St. Elisabeth University shelter, or Mea Culpa Dormitory shelters in Bratislava.

\section{Results}

3,131 homeless patients $(50.1 \%)$ presented with infectious diseases; commonest were upper respiratory tract infections (70.5\%) followed by skin and soft tissue infections $(20.5 \%)$ and ecto-parasites $(5.1 \%$, scabies as commonest). Only about $4.7 \%$ 
of all cases with severe ID were diagnosed; commonest diagnoses being pneumonia, infected necrosis of lower limbs after frostbites or leg ulcers. Only four suspected but not confirmed cases of TB have been described $(0.1 \%)$ which is in correlation with the average Slovak population with $0.01-0.1 \%$ prevalence (Tab.1). Concerning antimicrobials used amoxycilin, azitromycine, doxycycline and cotrimoxazole for SSTI and scabicides for ectoparasites with or without ivermectin has been commonly used. In 103 symptomatic homeless patients with lower RTI, swabs from nose and tonsils were obtained but no emergence of resistance in respiratory pathogens has been observed. Only one isolate of Penicillin resistant Pneumococcus (PRP) (1\%) and three MRSA (3.95\%) have been observed.

\section{Conclusion}

According to our 15 years epidemiological observation, homeless population does not represent major threat for other urban population in Bratislava. To decrease the incidence of upper RTI in homeless patients, vaccination against influenza a pneumococci mainly in patients over 65 years old should be considered and also for those staying in stationary shelters. Regular swabs from respiratory and gastrointestinal tract are advisable too.

\section{References}

1. GILBERT, M (2006) Outbreak in Alberta of community-acquired (USA300) methicillin-resistant Staphylococcus aureus in people with a history of drug use, homelessness or incarceration [Abstract]. CMAJ, 175. doi:10.1503/cmaj.051565.

2. BARTOSOVIC, I (2016). Some aspects of the health status of homeless people. Clinical Social Work and Health Intervention 7(1), 39-47. doi:10.22359/cswhi_7_1_04.
3. KALAVSKY E.: Do we need new ATB or new strategies, Neuroendocrinology let. vol 33, suppl,1,2013.33-34.

4. GALLAGHER TC, ANDERSON RM, KOEGEL P (1997) Determinants of regular sources of care among homeless adults in Los Angeles. Med Care. 35:814-30

5. PADGETT DK, STRUENING EL, ANDREWS H (1995) Predictors of emergency use by homeless adults in New York City: the influence of predisposing, enabling, and need factors. Soc Sci Med 41:547-56Sci.

6. ARCH S, LEAKE B, KNOWLES L, GELBERG L. (1998) Tuberculosis in homeless patients: potential for case finding in public emer-gency departments. Ann Emergency Med. 32:144-7.

7. SALIT SA, KUHN EM, HARTZ AJ (1998) Hospitalization costs associated with homelessness in New York City. New England J Med.; 338:1734-40.

8. PURCHARTOVA, D., PAVLU, D.: Influence of fine and gross motor skills after drinking alcohol, Rehabilitácia 4, XLIII(53), ISSN 0375-0922, s. 259-274

9. FAZEL, S, GEDDES, JR, KUSHEL, M (2014) The health of homeless people in high-income countries: descriptive epidemiology, health consequences, and clinical and policy recommendations. The Lancet, 384(9953), 1529-1540. doi:10.1016/s01406736(14)61132-6

10. MCCORMICK, B, WHITE, J (2016). Hospital care and costs for homeless people. Clinical Medicine, 16(6), 506-510. doi:10.7861/clinmedicine.16-6-506

11. MOJTOVA, M. 2014. Social work in the palliative hospice care; 1. vyd., Bratislava: SAP, 2014. 120 s. ISBN 978-80-89607-20-4.

12. RENGER, F., CZIRFUSZ, A. (2016): A first overview about the statusory and private health insurance in Germany. In: Health and Social Work. ISSN 13336-9326. Vol. 11, 2016, No 2, p. 20-26. 
13. DUDOVA Z, TRILISINSKAYA1 Y, JACKULIAKOVA T, JANKECHOVA M, SASVARY F, MATEL A, HAJJ ALI IA (2016) Six month follow up in communicable versus non-communicable diseases in an Iraqi refugee camp. Clinical Social Work and Health Intervention, 7 (3), 38 - 41. doi:10.22359/cswhi_7_3_10 